\title{
Exploring the Design of Tailored Virtual Reality Experiences for People with Dementia
}

\author{
James Hodge $^{1}$, Madeline Balaam ${ }^{2}$, Sandra Hastings ${ }^{3}$ and Kellie Morrissey ${ }^{1}$ \\ 1Open Lab, Newcastle University, Newcastle upon Tyne, UK, j.hodge1@ncl.ac.uk; k.morrissey@ncl.ac.uk \\ ${ }^{2}$ Media Technology \& Interaction Design, KTH Royal Institute of Technology, Stockholm, Sweden, balaam@kth.se \\ ${ }^{3}$ Silverline Memories, Newcastle upon Tyne, United Kingdom, sandra@silverlinememories.com
}

\begin{abstract}
Despite indications that recreational virtual reality (VR) experiences could be beneficial for people with dementia, this area remains unexplored in contrast to the body of work on neurological rehabilitation through VR in dementia. With recreational VR applications coming to the market for dementia, we must consider how VR experiences for people with dementia can be sensitively designed to provide comfortable and enriching experiences. Working with seven participants from a local dementia care charity, we outline some of the opportunities and challenges inherent to the design and use of VR experiences with people with dementia and their carers through an inductive thematic analysis. We also provide a series of future directions for work in VR and dementia: 1) careful physical design, 2) making room for sharing, 3) utilizing all senses, 4) personalization, and 5) positioning the person with dementia as an active participant.
\end{abstract}

\section{Author Keywords}

Dementia; care; virtual reality; augmented reality; creativity; experience; expression.

\section{ACM Classification Keywords}

H.5.m. Information interfaces and presentation (e.g., HCI).

\section{INTRODUCTION}

An initial focus in dementia and design research has been the tackling of cognitive deficits and other behavioural symptoms in people with dementia [37]; however, more recent research has followed more social and interpersonal lines, by paying attention to networks of care and aesthetic experience in dementia [39]. A similar initial focus on medicalisation has been faced by the development of virtual reality for clinical populations [12]. Virtual reality refers to the computer-generated simulation of a three-dimensional environment that can be interacted with by a person using equipment such as head-mounted displays (HMDs) or VR gloves [54, 32]. For those facing neurological impairments such as acquired brain injury through to learning disorders; neurological rehabilitation through VR has been a well-

This work is licensed under a Creative Commons

Attribution International 4.0 License.

CHI 2018, April 21-26, 2018, Montréal, QC, Canada. ACM ISBN 978-1-4503-5620-6/18/04.

https://doi.org/10.1145/3173574.3174088. researched topic for several years now [49], encompassing aspects such as executive dysfunction, memory impairment and attention deficits. Despite early indication that such measures are suitable only for those in the earlier stages of the condition, virtual reality for people with dementia in the later stages of the condition, who may benefit more from reminiscence and sensory stimulation rather than cognitive training [45, 62], has not been addressed.

Recent leaps in the field have seen virtual reality become an increasingly everyday technology; however, the potential for the field's impact upon healthcare has been anticipated for decades [49]. VR has been used in the treatment of psychological dysfunction including PTSD, phobias and eating and body image disorder, as well as in pain management to distract from uncomfortable procedures [18]. In the field of dementia, however, VR has been implicated overwhelmingly in the assessment and rehabilitation of cognitive processes [9], and more recently has been suggested as a method of delivery for exergames [10]. However, these applications ignore the potential for virtual reality as an expressive and creative medium to allow people with dementia to experience new, exciting, stimulating and potentially therapeutic environments entirely separate from the stress of cognitive assessment: a procedure which can be dehumanising for people living with new cognitive impairments [8].

This paper presents design research which aimed to explore opportunities and challenges inherent to the use of new (and often unfamiliar) VR technologies with people with dementia and their carers. We carried out two workshops with seven participants living with or caring for dementia in order to first learn how they experienced VR environments, trying out various environments, and discussing what they would like to see in a new set of VR environments. A second workshop focused on evaluating these new environments and suggesting more directions for future experiences. Within both workshops, we built in an extended engagement with Thomas and Janet, for whom we built a bespoke VR environment. The main contribution of this work is to provide the first set of design directions for creating VR experiences for and with people with dementia. As increasing numbers of recreational VR applications for dementia come to the market [55], it is important to ensure that these experiences are optimized for people with dementia, and to take advantage of the growing movement within HCI to respect the expressions of experience by people with 
dementia and their carers in designing new and sensitive technologies. This work therefore provides a starting point for new research in immersive experiences for people with dementia.

\section{BACKGROUND}

Design research in dementia has recently seen several ideological shifts, moving focus from work previously dedicated to improving 'gaps' in cognition for people with dementia to encompassing a more holistic picture of what it means to live well with a diagnosis of dementia [39]. The following section unpacks some of this design research to identify what has motivated this shift, before moving on to specific considerations drawn from previous work for virtual reality within the area of dementia.

\section{A new way of thinking about design and dementia}

Dementia is often represented as a 'loss of self' [25], or a condition which disrupts and fundamentally changes or even removes the identity of the person living with dementia [33]. Dementia is an umbrella term for a variety of symptoms, but is most usually used in reference to a progressive loss of memory in older age due to a degenerative brain condition $[1,21]$. The condition also brings with it symptoms of executive dysfunction such as disruptions in the ability to plan and carry out complex tasks. However, as the condition progresses, symptoms such as impairment of short term memory and other cognitive processes can worsen and be compounded by issues such as changes in communication styles (often moving to non-verbal forms of communication [26], and feelings of frustration, anger and uselessness as independence is curtailed by a move into living in care [43].

Recent work in design and dementia has had a concerted focus on creative methods of interaction [37] in order to offset the decline of communicative capabilities. Authors such as Lazar [29] and Morrissey [38] indicate that dementia is too often configured as a problem of cognition, when in fact many issues that arise as part of dementia are socially constructed [15]. For people with dementia, creative practice places emphasis on multimodal forms of communication and expression [1] - for example, the tactile feeling of working with clay or paint or materials, and the physical exertion and closeness to another experienced during dancing can provide opportunities to connect and express emotions and thoughts that are difficult to express in verbal conversation [46]. In their important ethnographic work on creativity in dementia care, Killick \& Craig [23] describe an encounter where a participants' engagement with his creative task had them wondering if he really had dementia at all; in this way, immersive, flow-inducing experiences have the potential to allow people with dementia to display skills that are often thought to be lost to the disease itself.

Killick \& Craig's work in creativity [23] with people with dementia has been compounded by a shift in design research which has seen an increased attention paid to creative expressions of choice and personhood. This is perhaps most strongly seen in the work of Jayne Wallace, who describes personhood as “"... something internally changing and externally nurtured through relational and social contexts, continually constructed by the peculiarities of experience and relationships" [60, p. 223]. Her design work with people with dementia, culminating in the redesign of a 'reminiscence room' in a dementia care ward [59], and the slow and involved process of designing digital jewellery to encapsulate the personhood of Gillian [58], newly diagnosed with dementia, has been pivotal in motivating this shift.

The potential for virtual or augmented reality environments for aesthetic appreciation in dementia is precipitated by [38, 40], an ethnographic study of creative musical experiences in care for people with dementia culminating in the design of digital tools to foster group movement within musical interactions. The authors describes how, one day, a resident named Fionnuala, watching a concert DVD of musician Daniel O'Donnell, is "interacting with the wall-hung television as though she were at the concert itself." Fionnuala sings along, waves at the singer as he winks into the camera, "blows kisses, and applauds wildly at the end of every song." While her disconnection from reality may seem disturbing, Fionnuala's engagement with media clearly allowed her a sense of pleasure and connection in the otherwise quiet and disconnected social environment of the care home.

Arts-based approaches to aesthetic experience in design research with people with dementia therefore clearly have the potential to position people with dementia in new and critical ways, which shine a light on their existing skills, proficiencies and preferences. In [38], music and performance is leveraged as a way of including people with dementia in design processes for technologies to support a sense of community in publicly-funded care. In [29], the authors draw on the concept of the "Third Hand," a practice in art therapy to allow therapists to attune to the creative wishes of the client, to understand how to empower creative work and sharing among older adults with cognitive impairments. What the aforementioned studies share is an approach to dementia not as a collection of deficits, but as an opportunity to use creative digital techniques to explore themes of personhood, community, immersion and expression.

What they also share is a commitment to the meaningful inclusion of people with dementia as co-designers in the creation of technologies that will affect their futures. This is a thread of research initiated by researchers such as Lindsay [31], Hendriks [16, 17] and Holbo [19], who leverage traditional participatory design techniques to interrogate what it means to include people with dementia as full participants in a co-design process. In doing so, research such as this necessarily reinvents what is seen as participative in order to incorporate a fuller spectrum of human experience and expression - for instance, paying attention to bodily movements instead of prioritizing verbal expressions. This movement towards a holistic consideration of participation in dementia is once more one which could prove valuable in 
evaluating the embodied and immersive experiences of virtual reality in dementia; however, previous work in the area is lacking, as is described in the following section.

\section{Media and virtual reality experiences in dementia}

Much design research in dementia has focused on the creative use of media in order to facilitate reminiscence or social interaction. In Wallace's aforementioned 'Tales of I' [59], a room in a dementia care becomes a 'reminiscence room', containing an old-style television and unit of shelves which were filled with thematically-ordered 'orbs', which, when placed on the television, would trigger a short film that was linked to the orb's theme - e.g., football or a day by the sea. Gaver et al [13] created the Photostroller, a mobile 'stroller' fitted with a television-like screen and dials which could be used to change media, similarly intended to engender chat within an aged care facility. Other technologies $[4,2]$ have used mobile devices in the design of reminiscence experiences for people with dementia, once more primarily using materials thought suitable for a general age range of participants with dementia.

The method of delivery for many of these media experiences has differed; however, virtual reality has not been explored as an immersive way to deliver media experiences for people with dementia. This is despite fairly widespread use in the rehabilitation of various neurological disorders, where it has found use through its ability to present ecologically valid testing and training scenarios, more controlled stimuli, and increased user participation [45]. Flynn et al [11] examined the feasibility of VR for people with dementia by testing the extent to which people with dementia could perform several functional activities (e.g., mailing a letter). The study indicated that people with dementia experienced a sense of presence in the virtual environment, felt in control of the interaction, and could use a joystick with ease. However, the study primarily tested functional abilities and collected little data surrounding users' views and experiences apart from reporting that the system was "well-received". Similar approaches are taken by Cushman et al [9] and van Shaik, Martyr, Blackman and Robinson [56], both of which use VR to assess wayfinding and report little on subjective experience of the virtual environments. Some of the best evidence we have on the use of VR or augmented reality comes from [51], whose observational work on recreating past memories for people with dementia through virtual worlds (using a Kinect system) indicates how participants "expressed a strong sense of "being inside" the [virtual world]" and who interpreted and interacted with the virtual world in ways which highlighted their sense of self.

A discussion of the use of VR in dementia by GarciaBetances et al [12] once more primarily focuses on the potential for VR in cognitive training or rehabilitation in dementia, though it devotes some space to the use of robots such as Paro and the concept of video respite, a videotape application that simulates the visit between an actor in the video and the person with dementia in order to provide respite for the caregiver as the person with dementia is occupied by the video. The authors conclude that the lack of use of VR within dementia is surprising, given its growth and anticipated growth as a clinical population. VR, they write, "can help us understand more about how persons with dementia interact with their environments - whether physically with the objects or socially with other people in their surroundings" [p. 12]. However, building on research by Siriaraya [51], we suggest that it can go further than this to become a technology which is enjoyable, enriching and imaginative in its own right for participants with dementia.

It is important to address the factors which may have held VR research in dementia back in such a significant way. In doing this, we will also articulate why we might expect VR experiences for people with dementia to differ from those created for neurotypical individuals. Rose, Brooks and Rizzo [45] suggest a cost-benefit analysis which looks at appropriateness (match to group characteristics), individual factors (immersion, functional abilities and generalizability), and ethics (the possibility of inducing harmful psychological consequences). Virtual reality can be overwhelming [30] many people report disorientation and motion sickness, which can deter users quite significantly. People with dementia live with cognitive and perceptual changes that can change the experience of immersive technologies [45]; beyond this, people with dementia and their carers are often considered to be "technophobes" who cannot use technology [37]. In fact, however, we have found that people with dementia and their carers generally can and do use technology, but in ways which we typically do not anticaipte and which deserve further study [28]. For these reasons, we believe that VR experiences for people with dementia and their carers must be designed in different and sensitive ways. Complicating this is a longstanding wish within HCI to protect people with dementia (and other vulnerable participants) [61], and if possible, to intervene only when we are assured our intervention will improve their lifeworld. However, this protectionist paradigm is not likely to radically improve the lives of people with dementia unless we are prepared to experiment within reason. The burgeoning call for work in dementia which speaks to the creative potential of people living with the condition is therefore reason enough to explore VR as a medium for enjoyable experiences.

\section{METHODOLOGY}

The primary aim of this project was to explore, via collaborative workshops, initial reactions to virtual reality environments for people living with dementia. A secondary aim was to design a personalized experience with a couple, wherein the wife was living with dementia, in order to explore, in some depth, how the technology could be harnessed to provide aesthetically engaging and pleasing virtual reality experiences. The study structure consisted of one scoping workshop, followed by a period of design and iteration based on participants' feedback, which was then followed by a further workshop to evaluate the completed virtual environments. Appended to both workshops was an 
extended engagement with Thomas and Janet, the couple living with dementia.

\section{Participants and setting}

We recruited 7 participants - three couples or family pairs where one person was living with dementia, and one older man who was attending the sessions on his own with a mild diagnosis of dementia. These participants were recruited through a local registered charity ('Bluebell Grove'), who had expressed an interest in virtual reality in dementia through social media channels. Participants are listed in table 1, with all participants with a diagnosis of dementia italicized. All participants who had a diagnosis of dementia had received a diagnosis of Alzheimer's type dementia, the most common cause of dementia.

\begin{tabular}{|l|l|}
\hline Name \& relationship & Age \\
\hline Dorothy (John's wife) & 82 \\
\hline John (Dorothy's husband) & 84 \\
\hline Lucy (Jessica's mother) & 83 \\
\hline Jessica (Lucy's daughter) & 51 \\
\hline Michael (Linda's husband) & 53 \\
\hline Linda (Michael's wife) & 53 \\
\hline Phillip (attending alone) & 54 \\
\hline
\end{tabular}

Table 1: participant information

Our small sample size is in part because of documented difficulties in recruiting people with dementia and their carers outside of formal care [15], as well as restrictions on informed consent in dementia [3]. Although only 4 people with dementia took part in the project, 3 participants were carers and it was our intention to include them as fully as possible; their participation is as valued as the person with dementia. This is based on a growing body of research that places emphasis on the social context of the person with dementia and the importance of including loved ones and carers as consultees in research, and in general, valuing them as part of the care ecology in dementia [8].

Bluebell Grove also provided the setting for the workshop. The charity describes itself as "the charity that provides places to go and things to do for people living with dementia" in the locality. The charity operates out of two main locations, both community centres, and shifts between these settings in order to ensure their services are accessible by a variety of residents of the locality. Our workshops were carried out as part of an afternoon tea session which ran weekly on Mondays, where participants are invited to attend to socialize, listen to music, and have tea and cakes. Many attended with family members; others were dropped off or attended alone; and still more attended from a local care home. The sessions were free to attend, and the level of dementia was mixed. The group adheres to the "Butterfly Method" [50], which means never correcting a person's beliefs or understanding. Bluebell Grove aims to simply "stay with the person in whatever time or space they believe themselves to be".

\section{Ethics}

Ethical approval was gained from Newcastle University's Ethics Committee. Particular attention was paid to configuring informed consent for people with dementia within this study. As the level of dementia was mixed within Bluebell Grove's afternoon tea groups, researchers had to be careful to carry out a capacity assessment as detailed in the Mental Capacity Act 2005 [3]. This assessment was carried out by Morrissey, who is a trained psychologist with five years' experience of working with people with dementia. The assessment consisted of four steps:

a) we told participants what was going to happen during the research meeting and why, and that the data may be used in a publication or written about in a thesis;

b) if participants seemed amenable to this, Morrissey asked, "can you tell me again what you understand you'll be doing as part of this meeting?" (or the equivalent phrased slightly differently);

c) she then talked about what would be good about them participating in this research and what could be bad/awkward/irritating for them;

d) she then told them that she was going to check again after the session and at the next workshop whether they are happy to continue in the study.

We also wished to ensure that the VR experiences were as safe as possible for our participants. We therefore reviewed literature describing the risks of VR [30] - prime among these were concerns around participants feeling nauseous after using the system, and participants moving around in the environment while wearing the headset and thus causing injury to themselves or others. We ensured that participants knew about the possibility of feeling sick, and also asked carers to try the headset before the person with dementia. We also ensured that participants were seated while trying the headset on, and ensured that all environments used were passive, relaxing environments. As an introduction to the study, we spoke in detail about what participants could expect by wearing the headset and experiencing the virtual environment. If a participant expressed doubt or wished not to take part, we respected their wishes and moved on.

\section{Workshops}

We carried out our workshops as a part of Bluebell Grove's afternoon tea sessions on Mondays. We held two workshops, organized flexibly in order to make space for normal afternoon tea activities to take place. Our aim within these workshops was to gather enough information about the participant group to create a series of virtual reality environments that could be interesting for them even after we had left - Laura, head of the charity, had expressed this wish strongly. In the first workshop, where participants were seated in a horseshoe shape, we visited each participant or 
participant couple one at a time, first taking the time to introduce ourselves and the research we were carrying out. We then described the process of trying out the VR experiences, showing participants pictures of people trying out the headset, and then displaying a selection of the headsets we had brought along (figure 1, above). We then asked if the participants would like to try the VR experience out. One simple VR experience was created for this workshop: a simple apartment, which allowed participants to turn their head and see out of a window. This was chosen for its neutral nature. After participants had tried out the VR experience, we spoke to them about what they had liked, disliked and would wish to see in the future in an experience such as this. In order to probe these conversations, we brought along several images of VR and real environments these were environments such as libraries, museums, forests, beaches, and cities. During workshop one, we spoke for an extended period with one couple, Thomas and Janet, who expressed a wish to have a bespoke environment created for Janet. Having recorded these conversations and also reflecting on the work later in field notes, we then spent a period of three weeks refining the VR environments to reflect the wishes of a) the larger group of participants, and b) the specific wishes of Thomas and Janet.

In the second workshop, we set the participants' seating up in a similar way, and moved around the group in the way we had before. For this workshop, we had created two different environments for the group at large: a park, based on a local park in the area, and a tropical beach with a horse running along the sand. Both environments were completed with a set of ambient sounds: i.e., wind, waves crashing, and birdsong. We had also created a bespoke environment for Thomas and Janet: a concert hall with her favourite singer performing onstage. We took a conversational approach once more in workshop two, approaching each participant group, reintroducing ourselves and then asking if they would like to try the VR experience. Once more, conversations were recorded and field notes were taken onsite and later fleshed out to inform our findings. A short interview was also carried out with Thomas and Janet in order to evaluate the bespoke VR experience in more depth.

\section{Data collection and analysis}

Data was collected through two main ways: 1) through careful field notes taken by Hodge, supplemented by audio recording of the sessions, and 2) through short interviews (> 30 mins) carried out with key participants (Thomas and Janet). These short interviews were semi-structured; Thomas and Janet were first asked about their past, their lives together as a couple, and the leisure activities they carried out together. A second interview with Thomas and Janet focused on an evaluation of the bespoke VR environment created for Janet.

These data were combined and analysed in NVivo using Thematic Analysis, which is a method for identifying and interpreting patterns across datasets, suited to exploring under-researched areas [6, 7]. We used an inductive approach to thematic analysis, where codes and themes were developed from the data content. The analysis aimed to answer the question, "what are some of the opportunities and challenges present when designing virtual reality experiences for people with dementia"?
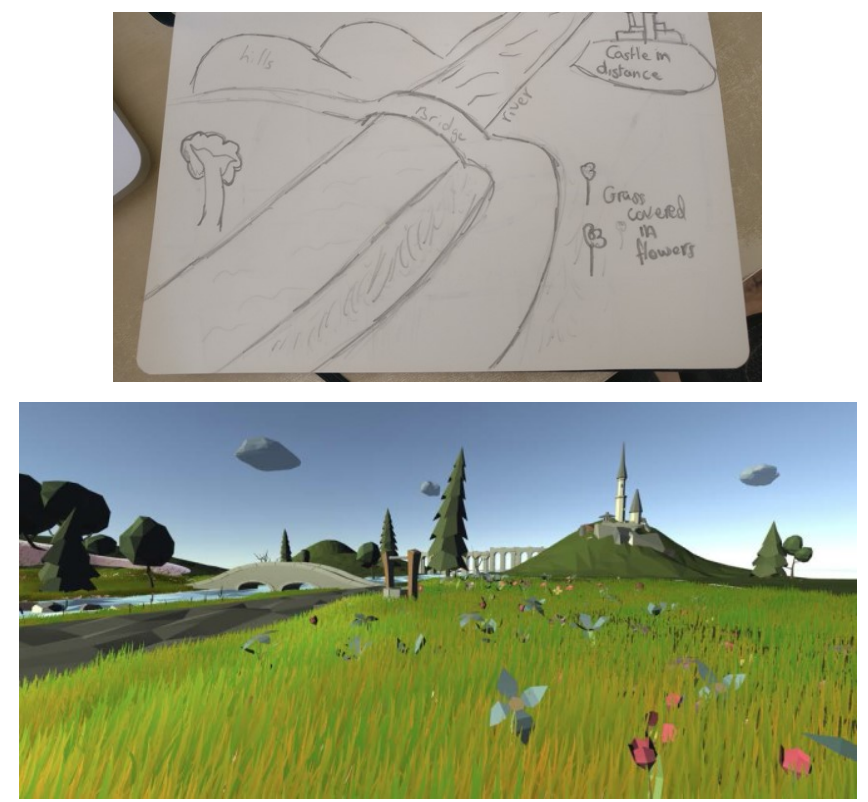

Figure 1: From sketching to final environment

The data analysis was primarily conducted by Hodge, in collaboration with Morrissey, both of whom were present at the research settings. We reviewed the data, the coding process, and the data coding through initial draftings and final write-ups. The data were read and reread several times, and then coding and analysis followed a four-step process. Data were initially coded using broad codes such as "fun," "relaxing," and "intrusive." The second round of coding then focused on identifying patterns of meaning by recoding the entire data set. Codes were then collated in order to develop potential themes. In the third step, initial themes were created from the codes, such as "freedom," "down time," and "togetherness". The fourth stage saw us refine themes further, through revisiting the full data set to determine the fit of themes.

\section{DESIGNING THE VR ENVIRONMENTS}

It is worthwhile to spend some time describing how these virtual environments were designed and created. All three environments - park, beach and concert hall - were created using Unity and scripted in $\mathrm{CH}$. We carefully planned the design of the environment in relation to the field of view of the participant. A key aim for us was the content to be easy for the participant to view; if we placed moving objects into the environment, we did not want the user to be rotating to follow the objects as this could cause them to feel sick. To further reduce risks of sickness or disorientation, we implemented a higher frame rate and used anti-aliasing; we 
also avoided the use of certain colours, and paid attention to the altitude of where the participant is in the environment.

Although we did not have sufficient time with our participants to effect a truly co-designed process, we did ensure we had enough time with Thomas and Janet in order to inform the building of a tailored environment for Janet. This was, in part, opportunistic - Laura had pointed the two out to us on one of our first visits, and Thomas had expressed a great interest in VR and a great proficiency with technology and 'gadgets', having set up their home with a large array of assistive technologies. In our first meeting, Thomas asked us to explain VR in as much detail as possible, explaining his own background with stereoscopy: "I want to know what about it first. It isn't 3D. It can't be ... 50 years ago, you could buy strips. I actually took my own, and printed them myself and it was wonderful and easy." We spent time with the couple over tea, learning about Janet's favourite songs and the then-current ways in which Thomas played this music for her - in curated Youtube playlists which he kept ready on his phone.

Thomas wished to try the VR experience for himself first, and we demonstrated the apartment. He was immediately impressed - "I can see how this is advertised as the miracle child" - and we went about discussing how we might build a concert hall around Janet's favourite musical experiences. The results of this engagement are discussed in our findings, below.

\section{FINDINGS}

Our thematic analysis of data gathered from the workshops centres around three main themes featuring codes identified at the semantic level: a) feeling foolish and feeling free, b) seeking to share a new world, and c) blending the old with the new.

\section{Feeling foolish and feeling free}

VR was a novelty to many of our participants, and even to the staff of Bluebell Grove, despite Laura's interest in using VR as part of the recreational activities of the day group. We had anticipated this to a certain extent, which is why we brought along a set of pictures to display the VR experience in its entirety before asking participants if they would like to try. Part of this process was also demonstrating the different ways of using the VR system - through a head-mounted display, and through a handheld Google Cardboard display. At this point, participants all decided on the handheld display. When queried about this, participants indicated that they found the large, purple, head-mounted display intimidating. Thomas indicated that his wife, Janet, would prefer a head-mounted display initially:

Thomas: I honestly think it wouldn't matter. I can't imagine that she has the patience to hold something like (Google Cardboard) that for a long time.

James: Do you think they're a bit scary to use?
Thomas: She won't use in ear headphones, I have a pair of wi-fi headphones. But she never uses them ... I'm the one with the toys. I can't imagine being happy with wearing that for long time.

However, in the second meeting with Thomas and Janet, the couple preferred to use the lighter Google Cardboard headset:

James: Do you think she could hold it by herself?

Thomas: She wouldn't be able to, but again, if it [the strapped headset] was a little lighter and with a strap then I think it would not be difficult. The weight [is a problem].

For the slight, frail Janet, both headsets were problematic due to their weight, and she could only use the Google Cardboard for a short period of time. Several others in the care group were pointed out by Laura as potentially interested in trying the system out, but later refused. James' field notes indicate that one attendee "wasn't keen on the idea of trying it ... she continuously shook her head when I asked if she would like to try it, however I told her, "it's fine if you don't" and showed her some of the pictures instead." However, other participants mentioned a fear of looking foolish or looking silly when wearing the head-mounted display. In an interaction with Michael and Linda, a couple where Michael was living with dementia, we discussed different VR headsets. "I prefer the smaller one", she indicated, gesturing to the Google Cardboard. When asked why, Linda mentioned that she found the larger ones to be "rather scary" despite acknowledging that they were easier to use for extended periods. The main issue indicated in field notes was that larger VR headsets "looked silly"; more participants mentioned they wouldn't like to be seen wearing the bigger versions, but did mention that they liked the comfort of the sponge casing.

For people with dementia, the fear of looking 'silly' is often a significant one. The first symptoms of dementia often manifest most visibly in social situations: losing small items such as keys or glasses or forgetting names of acquaintances. These changes in cognitive capacity and social abilities are often accompanied by changes in how people view the person with dementia - Nolan et al [41] report how people with dementia indicate that others tend to 'stand back from dementia, because it's too heavy' - and as the condition progresses, behavior may deviate even more markedly from the norm. In cases such as this, it is understandable that participants with dementia may want to protect their dignity by not taking part in activities which have the capacity to make them seem 'silly'. Beyond this, the unfamiliarity of the experience may have been prohibitive, even after spending a period of time describing the experience and demonstrating it ourselves.

Running counter to initial reticence around trying out the VR environments is a sense of freedom and enjoyment seemingly enjoyed by participants once they tried the headset and the environment. James' field notes indicate that, once using the headset, participant Phillip's "attitude towards it changed 
completely." Phillip's dementia was mild, but his verbal ability was compromised by a recent stroke. Still, our field notes report his verbalisations during the use of the headset:

"He said 'yes' occasionally and his facial expression became a lot more relaxed and seemed to smile more often than before. ... We played the sound of calm waves coming in and out on the shore and the sound of seagulls in the background. As he was listening to the sound of beach he seemed very settled and didn't want to stop."

A similar enlivening effect was seen in the bespoke design of the VR environment for Thomas and Janet. Similarly rarely verbal, Janet was a fan of country music and Shania Twain in particular. Having spoken to the couple in depth in earlier sessions, we followed their requests to create a simple concert environment that replicated the sense of being within a large concert hall. The music of Shania Twain was played in the background and on a screen backing a figure of the singer on a stage below. Due to her slightness, Thomas aided us in helping to hold the VR system to Janet's eyes for her to try out the experience. Once more returning to field notes, James' notes indicate that "straight away [Janet] started to sing. It sounded to me that she was trying to repeat the lyrics ... [and] changed her body movement completely. Janet started to try to hold the Google Cardboard as well which indicated she didn't want to stop the experience. [Afterwards] she seemed very happy and you could tell from her body movement that she had changed in mood completely."

[38] have indicated at length how music can transform relationships between people with dementia and recall abilities and preferences long since believed to be lost. Here, we can see how sensitively designed VR experiences can act as a similar window onto the abilities and preferences of people with dementia. When verbal abilities wane, other abilities come to the fore [29] - and here we see evidence that carefully designed VR experiences can help us to understand the experiences of people who are now less able to voice these experiences verbally. Beyond this, this freeing effect is clearly pleasurable for participants who can engage in enjoyable activities; later, reflecting on the experience, Thomas mentions that Janet has "always sang and whistled. She can sing along to songs as long as she remembers the words. The aesthetic of the theatre was a great idea and gives a sense of space."

\section{Seeking to share a new world}

Most of the participants we involved in the project came along as couples or parent-child pairs. Many of the participants reported that the afternoon tea sessions at Bluebell Grove were an opportunity to spend meaningful time in public with their loved ones, but also to access social support and advice from professional carers and from others facing the challenges of dementia. Sharing experiences was important for our participants, many of whom expressed a wish to be able to share in the same 'live' VR experience as their partner or parent. When asked about this, participants shared experiences from their lives which indicated that meaningful shared experiences with their loved one with dementia had changed recently or decreased in frequency. For instance, Linda, whose husband Michael had dementia, mentioned that the couple no longer drove and had to use public transport, due to Michael's dementia. This meant that the two could not visit favoured locations together, and so she indicated that the VR park and VR beach could be used to supplement their recreational activities and allow them to experience a semblance of the sorts of activities which used to mean very much to them.

In speaking with Thomas and Janet, the need for a shared experience was expressed extremely strongly. We asked Thomas to share some of his history with Janet in order to help inform the design of the VR environment:

"I'm always trying to find something that can entertain her, so it's a fairly lonely existence but if it's something that we could share that'd be great. There's so little, even watching television."

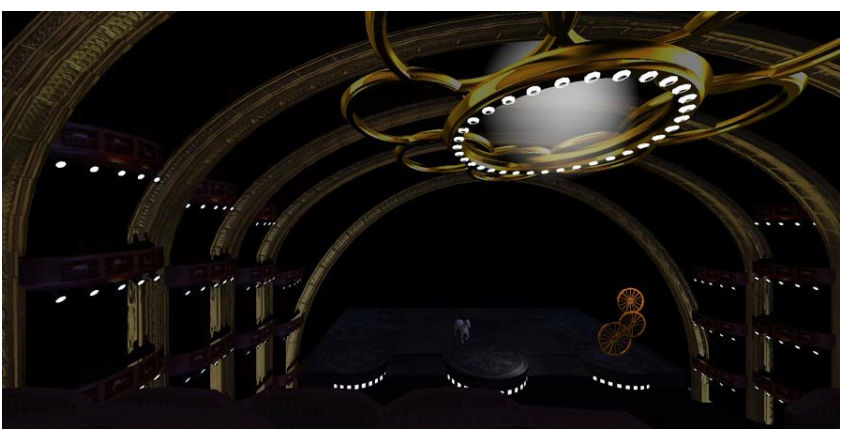

Figure 2: creating the concert venue for Janet

Thomas' story of his wife's cognitive decline is an affecting one due to the importance he places on entertaining his wife as a way to share an experience with her. His frustration is evident - he states that "she can't do a damn thing" - but still seeks to share an experience with his wife. Other duos had excited exchanges surrounding the VR system - Lucy and Jessica were a mother and daughter couple attending the tea session together. Jessica's excitement at trying the system which she had only seen on television prior to this spurred her mother on to also participate with enthusiasm. James' field notes here indicate that:

"With encouragement from her daughter it seemed a lot easier to ask Lucy to try it on. As Lucy used it, straight away she started to say what she could see - "lighthouse, rocks, sand, sea, boat" - as she moved around the virtual environment. She then tried out the park environment and loved the sounds of the birds in the background. Again, she started to list off the objects she could see. ... We then went on to talk off-topic to the virtual reality systems by talking about university and Jessica's kids going to university."

Here, the initial reticence displayed in being confronted with an unfamiliar system dissipated when a loved one - here, Jessica, an adult daughter - served as an entry point into the 
experience. This shared experience then allowed for easy conversation with the two afterwards. In this way, the technology may serve as a 'ticket to talk' [5] - a novel experience that provides an excuse or conduit for conversation.

\section{Blending the old with the new}

A common objective in much design research with people with dementia is to provide familiar experiences or use familiar media. This is usually employed as an objective due to the nature of dementia - short-term memory is often lost first, with long-term memories affected last of all. There is also a commonly-recognised 'reminiscence bump' observed between the ages of 18-30 [22], where memories encoded in this period seem to be easier to retrieve in later life. As a result, much design research in dementia has attempted to 'cast back' to earlier, positive memories [4, 2] - or even to modify the physical design of objects in order to make them appear 'older' $[59,60]$. The environments we created were not set in any particular time period - and notably, none were requested by the participants that we worked with. However, participants did report interesting tensions between old and new experiences when interacting with the VR system.

Thomas sought new ways for Janet to express herself now that her dementia had progressed and she is unable to take part in the sorts of activities she carried out in the past:

"I was an architect, so [I've] always been able to express [myself] manually but Janet couldn't. So, all she has done is listen to music and play music. She used to be in a choir so it's been a big part of her. She can really enjoy it."

In the absence of Janet's more usual ways of engaging with music, Thomas suggested that a theatre was an effective way of allowing her to experience something approaching live music once more. When we asked him to suggest the sort of music Janet would like, he used a pre-loaded YouTube playlist to inform us.

The careful design of the VR theatre environment allowed Janet to experience aspects of a familiar experience in an entirely new setting. Her reaction is immediately positive; a transcription of the session where she tries the bespoke environment for the first time indicates that she begins singing immediately, moves her head to look around the theatre of her own accord, and then says "boom!" before laughing merrily. Thomas then reflects on how he could see the system being used for others with dementia:

"Some people, I can imagine people would use it if they had the physical strength and if they're not so far down the road and could be watching football - where you could be in the crowd. You'd see the people and feel the atmosphere. I used to go to the rugby matches and the atmosphere and singing and so many songs echoing across the stadium was inspiring, so that kind of thing."

Having seen his wife experience a new world via the VR system, Thomas indicates the sorts of experiences that would be "inspiring" for others with dementia: those which held emotional significance for them but which perhaps their physicality now did not allow them to take part in. Thomas places the person with dementia here in an active role despite their lack of physical ability - they are the ones experiencing the atmosphere of the stadium in all its dimensions and making sense of their experience in terms of their felt history [36].

In an earlier theme, we describe how Michael and Linda indicated that a VR system could act as a missing link between their current situation - having to depend on public transport - and their past, where they visited many favourite places together. Another couple, John and Ruby, also tried the system out and reported enjoying it. However, from our field notes, Ruby indicated that "while she found it extremely interesting, she'd never use something like virtual reality as she'd rather just go to the beach as it's only a 10 minute drive away." Although Ruby mentioned that she could see others using the system, she stated a preference for the "real thing." She implicitly raises a question about the sorts of things we create virtual reality 'around' - we created pleasant but everyday environments for this project due to the initial wishes of our participants but also because we did not wish to show anything bombastic or frightening too early in our participants' journey with virtual reality. It's worthwhile to note that a priest visiting the group on one of the occasions we visited mentioned how a VR system could allow people to attend church from afar, but also to experience praying in new ways with the use of creative graphics and visuals, raising the possibility of VR to allow people with dementia to experience meaningful, personal situations in entirely new ways.

\section{DISCUSSION}

Our thematic analysis of textual data from our workshops and engagements with participants point towards three themes with codes identified at the semantic level: 1) feeling foolish and feeling free, 2) seeking to share a new experience, and 3) blending the old with the new. These themes indicate three areas where recreational VR experiences for people with dementia can be designed and can be improved. However, it is also worthwhile to position our work within previous design research for people with dementia.

Although Laura had approached us in order to talk about designing VR experiences for her clients with dementia, we did not anticipate the degree to which participants saw virtual reality as an opportunity to be together in meaningful ways with their loved ones. The common preconception is that virtual reality is an isolating experience [42]; a popular news outlet writes that "once you put on the headset, you're separated from the world around you ... [e]ven at home, where one can fully appreciate VR's capacity for immersion while in the comfort and safety of your living room, it's still equally isolating - a far cry from family movie night or a games night with friends." Our workshops have indicated 
that this isn't necessarily true: short, playful VR experiences can be shared even in an ad-hoc basis with friends and family, and people can discuss what they are experiencing even while they are experiencing it.

In our workshops, the VR system was an inherently social interaction and served as a point to talk about. As mentioned above, this has also been anticipated by Blythe et al [5], who refer to "tickets to talk" after Harvey Sacks [48]. In their care home study, several technological tickets were used: 1) Google Earth Biographies, 2) Archive Photography Reminiscence, and 3) Digital Curios and Novelties. Conversing in dementia care can be difficult, even if people know each other well - McNaney et al [35] indicate that family carers are often not deterred by the communicative changes in dementia; instead, they are often unsure of what to talk about. VR as an experience or as a way of presenting interesting media may therefore serve as another ticket to talk - particularly seeing as the technology is gaining in its ubiquity and dropping in price.

In designing VR experiences for people with dementia, should we create environments which are novel and surprising, or stick to familiarity and 'old' experiences, given the participant group we are working with? The environments visited in this study were outside of time for the most part - beaches, parks, and concert halls - and the short time we had to engage with our participants meant that we did not have enough time to tailor elements of the environments to particular periods. When we design for and with people with dementia in general, we tend to create objects and interfaces which feel 'old' - this is ostensibly to ensure some familiarity for the person with dementia. Familiarity is often an aesthetic choice, and certainly key when it comes to function - if we want people to be able to use systems with any degree of complexity, we need to ensure their affordances are familiar and make sense however, VR offers the potential to go beyond familiarity to offer transcendental experiences. A final section of our analysis discusses a priest's wish for a VR system to deliver a new way of praying. It is also possible to imagine how elements of light and sensory therapy, as deployed in a Snoezelan room (a controlled multisensory room aimed at stimulating and soothing people with dementia or other cognitive issues), could be parlayed into an immersive virtual reality experience which provides even greater immersion. In this way, VR experiences in dementia do not need to be familiar in order to be enriching.

It is also worthwhile to reflect on what it means to carry out risky research in dementia. The bulk of design research in dementia has been carried out in sensitive and "safe" spaces - some of the most participative work has been carried out to co-create aesthetic objects with participants' own families [60], whereas other design research has focused on the curation and display of generic media for reminiscence and chat $[4,2]$, or the tangible companionship of social robots [27]. When a piece of technological design does seek to challenge a person with dementia, it is often in order to actively seek some larger goal of cognitive rehabilitation or training via gamification [37]; these sorts of challenges have been criticized by [34] as creating the sorts of games that people will not want to play. We argue that there is an inbetween space to be designed for - one which does not rely on familiar or even intentionally 'old' interactions, but instead makes full use of the range of technological features and interactions now available to us in order to allow people with dementia to access a spectrum of sensory experiences. We draw this line in direct contrast with design research that aims to allow participants to reminisce or dwell on past memories, or research which aims only to focus on cognitive state. It can indeed be argued that restricting participants with dementia to a certain set of interactions is constitutive of the same sort of infantilisation people with dementia face all too often.

\section{Implications for design}

Given the relative newness of this area as an area for design and design research, the contribution of some future directions for the design of VR systems for people with dementia is warranted. This section lays out five future directions for design work in the area to ensure that these systems are designed in sensitive and enriching ways for people with dementia.

\section{Pay attention to the physical design of systems.}

Our findings point to a significant concern on the behalf of our participants regarding how they might look while wearing a strapped headset. We were demonstrating the VR experiences in a social setting - during an afternoon tea - and as such the presence of others in the room may have heightened these concerns for participants. However, beyond the "silly" look of the headsets, participants also expressed concerns about the weight of the headsets and preferred to use the handheld Google Cardboard. Future designs should take these presentation concerns into account, and perhaps think about how the headsets could be made to look more attractive and normal - e.g., by embedding the display into a set of binoculars, or a lorgnette.

\section{Make room for shared experiences.}

One of the greatest desire expressed by our participants was the wish for shared experiences with their loved ones. As dementia progresses and both memory and communicative abilities are affected, the opportunities for shared, meaningful interactions can become scarce. Many carers in our workshops expressed appreciation while watching their loved ones interact with the virtual worlds, and wished that they could have joined them in some way. Allowing carers to demo the system before the person with dementia tried it allowed carers to help direct their loved one around the environment by pointing out features easily missed. An easy addition of a screen displaying the same view as the headset could allow for even greater shared experiences; however, we must guard against implementing elements of testing into environments intended to be pleasurable. In interacting with Ruby and John, Ruby assumed that the VR experience was 
intended as a cognitive training tool and began to 'test' John's recall of the environment before we explained otherwise. To implement elements of training or testing into these environments would mean returning to a medicalized view of the person with dementia as a set of deficits, rather than a fully realized person with needs and desires.

\section{Use the full spectrum of sensory experiences.}

Age-related decline means that eyesight and other senses can also deteriorate alongside cognitive ability. However, the opposite can be true: as memory deteriorates or the ability to speak declines, sounds (including music) and physical touch can become extremely important. This has been elaborated upon at length by $[38,60]$. In many of the cases above, we indicate how ambient sounds added a great deal to the nature landscapes we demonstrated, while music was a key part of personalizing the concert for Janet. Further building on spatial audio or other shared experience features means that these senses could be brought more meaningfully into these experiences in order to make the best use of the strengths and abilities remaining within the person with dementia.

\section{Personalise the old and the new.}

Our approach was to spend some time getting to know our participants in an initial workshop that would then give us enough information to tailor aspects of the resulting environments to the group's preferences. Due to time restraints, we only had time to do a focused tailored design for one set of participants, Thomas and Janet. However, it would be possible to build on the sorts of environments we created as 'templates' - beaches, parks, and concert halls and build in a set of more specific elements that could be swapped in and out by carers. For instance, a sunny day at an island beach could become a misty day on a coastal shore, with the tweeting of birds becoming the cawing of seagulls; a concert featuring Shania Twain could easily become one with Leonard Cohen, and so on. Building these features into an interface which allowed a carer to configure these could also add to the sharing element which we discussed as important earlier.

5. Ensure the active inclusion of the participant with dementia. Many of the stated risks of virtual reality point to a fear that the person with dementia could be 'hooked up' [42] to a VR system which replaces social interaction. With increasing reports concerning the rise of excess disability - disability incurred beyond the decline that could be expected through the condition of dementia - in our care homes, this fear is perhaps sensible. We therefore need to ensure that we take a critical approach to the VR environments we create for people with dementia; as we should do with any of the technologies we create [28]. In our findings section, Thomas paints a picture of the sort of VR system he would like to see for those with dementia - one where the person is able to revisit meaningful experiences not as a passive observer, but as the focal point who drives along the experience in all its richness. We need to ensure that VR experiences we create for people with dementia consistently have the person at their centre - not to provide a series of challenges, but always to enrich their lives and provide safe, comfortable, evocative experiences.

\section{CONCLUSION}

This paper has presented a study with 7 participants focusing on the design of novel virtual reality environments for people with dementia and their carers. Through iterative design workshops, including an extended engagement with a couple living with dementia, we discuss the design of three different VR environments. Our thematic analysis of textual data from these workshops has produced three themes: feeling foolish and feeling free, seeking to share new worlds, and blending the old with the new. We close with a discussion of five indications for future design in the area: 1) physical design of systems, 2) making room for sharing, 3) utilizing all senses, 4) personalization, and 5) positioning the person with dementia as an active participant. Finally, we call for design to occupy a new space in technologies for dementia - one which is not occupied by the past or focused on perceived cognitive deficits, but oriented towards the present and ready to make use of a full spectrum of interactivity.

\section{ACKNOWLEDGEMENTS}

We would like to thank all participating clients of Bluebell Grove as well as to staff of the charity for their time and interest, especially to Sandra Hastings. This work was funded under the EPSRC Centre for Doctoral Training in Digital Civics at Newcastle University (EP/L016176/1). Data supporting this publication is not openly available due to confidentiality consideration. Access may be possible under appropriate agreement. Additional metadata record at http://dx.doi.org/10.17634/154300-69.

\section{REFERENCES}

1. Donna Algase, Cormelia Beck, Ann Kolanowski, Ann Whall, Stanley Berent, Kathy Richards, and Elizabeth Beattie. 1996. Need-driven dementia-compromised behavior: An alternative view of disruptive behavior. American Journal of Alzheimer's Disease 11, no. 6 (1996): 10-19.

2. Norman Alm, Richard Dye, Gary Gowans, Jim Campbell, Arlene Astell, and Maggie Ellis. 2003. Designing an interface usable by people with dementia. In ACM SIGCAPH Computers and the Physically Handicapped, no. 73-74, pp. 156-157.

3. Alzheimer's Society of Ireland. 2016. Mental Capacity Act 2005. Retrieved from:

https://www.alzheimers.org.uk/site/scripts/documents_in fo.php?documentID=354, 23rd March 2016

4. Arlene Astell, Brian Malone, Gary Williams, Faustina Hwang, and Margaret Ellis. 2014. Leveraging everyday technology for people living with dementia: a case study. Journal of Assistive Technologies 8 (4): pp. 164176.

5. Mark Blythe, Peter Wright, John Bowers, Andy Boucher, Nadine Jarvis, Phil Reynolds, and Bill Gaver. 2010. Age and experience: ludic engagement in a 
residential care setting. In Proceedings of the 8th ACM Conference on Designing Interactive Systems (DIS '10). ACM, New York, NY, USA, 161-170. DOI=http://dx.doi.org/10.1145/1858171.1858200

6. Virginia Braun and Victoria Clarke. 2006. Using thematic analysis in psychology. Qualitative Research in Psychology, 3 (2): pp. 77-101.

7. Virginia Braun and Victoria Clarke. 2014. What can "thematic analysis" offer health and wellbeing researchers? International Journal of Qualitative Studies on Health and Well-being, 9.

8. Barbara Chenoweth and Beth Spencer. 1986. Dementia: The experience of family caregivers. The Gerontologist, 26 (3): pp. 267-272.

9. Laura A. Cushman, Karen Stein, and Charles J. Duffy. 2008. Detecting navigational deficits in cognitive aging and Alzheimer disease using virtual reality. Neurology, 71 (12): pp. 888-895.

10. Samanatha Finkelstein, Andrea Nickel, Zachary Lipps, Tiffany Barnes, Zachary Wartell, and Evan A. Suma. 2011. Astrojumper: Motivating exercise with an immersive virtual reality exergame. Presence: Teleoperators and Virtual Environments, 20 (1): pp. 7892.

11. Darren Flynn, Paul Van Schaik, Tim Blackman, Clive Femcott, Brian Hobbs, and Carlos Calderon. 2003. Developing a virtual reality-based methodology for people with dementia: a feasibility study. CyberPsychology \& Behavior, 6 (6): pp. 591-611.

12. Rebeca García-Betances, María Teresa Arredondo Waldmeyer, Giuseppe Fico, and María Fernanda Cabrera-Umpiérrez. 2015. A succinct overview of virtual reality technology use in Alzheimer's disease. Frontiers in Aging Neuroscience, 7.

13. William Gaver, Andy Boucher, John Bowers, Mark Blythe, Nadine Jarvis, David Cameron, Tobie Kerridge, Alex Wilkie, Robert Phillips, and Peter Wright. 2011. The photostroller: supporting diverse care home residents in engaging with the world. In Proceedings of the SIGCHI Conference on Human Factors in Computing Systems (CHI '11). ACM, New York, NY, USA, 1757-1766. DOI: https://doi.org/10.1145/1978942.1979198

14. Andrea Gruneir, Kate L. Lapane, Susan C. Miller, and Vincent Mor. 2008. Is dementia special care really special? A new look at an old question. Journal of the American Geriatrics Society, 56 (2): pp. 199-205.

15. Nancy Harding and Colin Palfrey. 1997. The social construction of dementia: Confused professionals?. London: MacMillan Publications.

16. Niels Hendriks, Liesbeth Huybrechts, Andrea Wilkinson, and Karin Slegers. 2014. Challenges in doing participatory design with people with dementia. In
Proceedings of the 13th Participatory Design Conference: Short Papers, Industry Cases, Workshop Descriptions, Doctoral Consortium papers, and Keynote abstracts - Volume 2 (PDC '14), Vol. 2. ACM, New York, NY, USA, 33-36. DOI=http://dx.doi.org/10.1145/2662155.2662196

17. Niels Hendriks, Frederik Truyen, and Erik Duval. 2013. Designing with dementia: Guidelines for participatory design together with persons with dementia. In IFIP Conference on Human-Computer Interaction, pp. 649666. Springer, Berlin, Heidelberg.

18. Hunter G. Hoffman, Jason N. Doctor, David R. Patterson, Gretchen J. Carrougher, and Thomas A. Furness. 2000. Virtual reality as an adjunctive pain control during burn wound care in adolescent patients. Pain, 85 (1): pp. 305-309.

19. Kristine Holbø, Silje Bøthun, and Yngve Dahl. 2013. Safe walking technology for people with dementia: what do they want?. In Proceedings of the 15th International ACM SIGACCESS Conference on Computers and Accessibility (ASSETS '13). ACM, New York, NY, USA, , Article 21,8 pages. DOI: http://dx.doi.org/10.1145/2513383.2513434

20. Yu-Jun Hong, Chen-Yuan Hsieh, Keng-Ta Yang, and Liwei Chan. 2017. Wakeboarding: an exertion game in virtual reality. In ACM SIGGRAPH 2017 VR Village (SIGGRAPH '17). ACM, New York, NY, USA, Article 15, 2 pages. DOI: https://doi.org/10.1145/3089269.3089271

21. Tammy Hopper, Michelle Bourgeois, Jane Pimentel, Constance Dean Qualls, Ellen Hickey, Tobi Frymark, and Tracy Schooling. 2013. An evidence-based systematic review on cognitive interventions for individuals with dementia. American Journal of SpeechLanguage Pathology, 22 (1): pp. 126-145.

22. Ashok Jansari and Alan J. Parkin. 1996. Things that go bump in your life: Explaining the reminiscence bump in autobiographical memory. Psychology and Aging, 11 (1): pp. 85.

23. John Killick and Claire Craig. (2011). Creativity and Communication in Persons with Dementia: A Practical Guide. London: Jessica Kingsley Publishers.

24. Tatsuya Kodera, Naoto Tani, Jun Morita, Naoya Maeda, Kazuna Tsuboi, Motoko Kanegae, Yukiko Shinozuka, Sho Shimamura, Kadoki Kubo, Yusuke Nakayama, Jaejun Lee, Maxime Pruneau, Hideo Saito, and Maki Sugimoto. 2014. Virtual rope slider. In Proceedings of the 2014 Virtual Reality International Conference (VRIC '14). ACM, New York, NY, USA, , Article 36,4 pages. DOI=http://dx.doi.org/10.1145/2617841.2620725

25. Pia Kontos. 2004. Ethnographic reflections on selfhood, embodiment and Alzheimer's disease. Ageing \& Society, 24 (6): pp. 829-849. 
26. Michael Kopelman. 1991. Non-verbal, short-term forgetting in the alcoholic Korsakoff syndrome and Alzheimer-type dementia. Neuropsychologia, 29(8), 737-747.

27. Amanda Lazar, Hilaire J. Thompson, Anne Marie Piper, and George Demiris. 2016. Rethinking the design of robotic pets for older adults. In Proceedings of the 2016 ACM Conference on Designing Interactive Systems, pp. 1034-1046.

28. Amanda Lazar, Caroline Edasis, and Anne Marie Piper. 2017. A Critical Lens on Dementia and Design in HCI. In Proceedings of the 2017 CHI Conference on Human Factors in Computing Systems (CHI '17). ACM, New York, NY, USA, 2175-2188. DOI: https://doi.org/10.1145/3025453.3025522

29. Amanda Lazar, Raymundo Cornejo, Caroline Edasis, and Anne Marie Piper. 2016. Designing for the Third Hand: Empowering Older Adults with Cognitive Impairment through Creating and Sharing. In Proceedings of the 2016 ACM Conference on Designing Interactive Systems (DIS '16). ACM, New York, NY, USA, 1047-1058. DOI: https://doi.org/10.1145/2901790.2901854

30. Christopher H. Lewis, and Michael J. Griffin. 1997. Human factors consideration in clinical applications of virtual reality. Studies in Health Technology and Informatics, pp. 35-58.

31. Stephen Lindsay, Katie Brittain, Daniel Jackson, Cassim Ladha, Karim Ladha, and Patrick Olivier. 2012. Empathy, participatory design and people with dementia. In Proceedings of the SIGCHI Conference on Human Factors in Computing Systems (CHI '12). ACM, New York, NY, USA, 521-530. DOI: http://dx.doi.org/10.1145/2207676.2207749

32. Zhou Ma and Pinhas Ben-Tzvi. 2015. Design and optimization of a five-finger haptic glove mechanism. Journal of Mechanisms and Robotics, 7 (4).

33. Catherine Malabou. 2012. The new wounded: From neurosis to brain damage. Fordham University Press.

34. Joe Marshall and Conor Linehan. 2017. Misrepresentation of Health Research in Exertion Games Literature. In Proceedings of the 2017 CHI Conference on Human Factors in Computing Systems(CHI '17). ACM, New York, NY, USA, 48994910. DOI: https://doi.org/10.1145/3025453.3025691

35. Roisin McNaney, John Vines, Jamie Mercer, Leon Mexter, Daniel Welsh, and Tony Young. 2017. DemYouth: Co-Designing and Enacting Tools to Support Young People's Engagement with People with Dementia. In Proceedings of the 2017 CHI Conference on Human Factors in Computing Systems (CHI '17). ACM, New York, NY, USA, 1313-1325. DOI: https://doi.org/10.1145/3025453.3025558
36. John McCarthy and Peter Wright. 2004. Technology as Experience. Cambridge: MIT Press.

37. Kellie Morrissey, Amanda Lazar, Jennifer Boger, and Austin Toombs. 2017. HCIxDementia Workshop: The Role of Technology and Design in Dementia. In Proceedings of the 2017 CHI Conference Extended Abstracts on Human Factors in Computing Systems (CHI EA '17). ACM, New York, NY, USA, 484-491. DOI: https://doi.org/10.1145/3027063.3027083

38. Kellie Morrissey, Gavin Wood, David Green, Nadia Pantidi, and John McCarthy. 2016. 'I'm a rambler, I'm a gambler, I'm a long way from home': The Place of Props, Music, and Design in Dementia Care. In Proceedings of the 2016 ACM Conference on Designing Interactive Systems(DIS '16). ACM, New York, NY, USA, 1008-1020. DOI: https://doi.org/10.1145/2901790.2901798

39. Kellie Morrissey, John McCarthy, and Nadia Pantidi. 2017. The Value of Experience-Centred Design Approaches in Dementia Research Contexts. In Proceedings of the 2017 CHI Conference on Human Factors in Computing Systems (CHI '17). ACM, New York, NY, USA, 1326-1338. DOI: https://doi.org/10.1145/3025453.3025527

40. Kellie Morrissey and John McCarthy. 2015. Creative and Opportunistic Use of Everyday Music Technologies in a Dementia Care Unit. In Proceedings of the 2015 ACM SIGCHI Conference on Creativity and Cognition (C\&C '15). ACM, New York, NY, USA, 295-298. DOI=http://dx.doi.org/10.1145/2757226.2757228

41. Louise Nolan, Mary McCarron, Phillip McCallion, and Jo Murphy-Lawless. 2006. Perceptions of stigma in dementia: an exploratory study. Retrieved from: https://www.lenus.ie/hse/handle/10147/299918, June 17th, 2015.

42. Ramona Pringle. 2017. Virtual reality is still too isolating to be 'the next big thing' in tech. Retrieved from: http://www.cbc.ca/news/opinion/vr-isolation1.3980539, 14th September 2017.

43. Deborah Reed-Danahay. 2001. 'This is your home now!': conceptualizing location and dislocation in a dementia unit. Qualitative Research, 1(1), 47-63.

44. Adi Robertson. 2016. Dear Angelica is Oculus' third virtual reality film, and it's being made in VR. Retrieved from: https:/www.theverge.com/2016/1/26/10833340/dearangelica-quill-oculus-story-studio-sundance-2016, 1st September 2017.

45. F. David Rose, Barbara M. Brooks, and Albert A. Rizzo. 2005. Virtual reality in brain damage rehabilitation. Cyberpsychology \& Behavior, 8 (3): pp. 241-262. 
46. Paula Rylatt. 2012. The benefits of creative therapy for people with dementia. Nursing Standard, 26 (33): pp. 42-47.

47. Steven R. Sabat. 1994. Excess disability and malignant social psychology: A case study of Alzheimer's disease. Journal of Community \& Applied Social Psychology, 4 (3): pp. 157-166.

48. Harvey Sacks. 1992. Lectures on Conversation: Volumes I and II. Oxford: Blackwell.

49. Maria T. Schultheis and Albert A. Rizzo. 2001. The application of virtual reality technology in rehabilitation. Rehabilitation Psychology, 46 (3).

50. David Sheard. 2015. Mattering in a dementia care home - The Butterfly Approach. Retrieved from: http://www.dementiacarematters.com/pdf/modern.pdf, 18th August 2017.

51. Panote Siriaraya and Chee Siang Ang. 2014. Recreating living experiences from past memories through virtual worlds for people with dementia. In Proceedings of the SIGCHI Conference on Human Factors in Computing Systems (CHI '14). ACM, New York, NY, USA, 39773986. DOI: https://doi.org/10.1145/2556288.2557035

52. Nobuhisa Tanaka and Hideyuki Takagi. 2004. Virtual reality environment design of managing both presence and virtual reality sickness. Journal of Physiological Anthropology and Applied Human Science, 23 (6): pp. 313-317.

53. Ioannis Tarnanas, Winfried Schlee, Magda Tsolaki, René Müri, Urs Mosimann, and Tobias Nef. 2013. Ecological validity of virtual reality daily living activities screening for early dementia: longitudinal study. JMIR Serious Games 1 (1).

54. Michael J. Tarr and William H. Warren. 2002. Virtual reality in behavioral neuroscience and beyond. Nature Neuroscience, 5 (11).

55. Tribemix. 2017. Commercial immersive virtual reality for people with dementia. Retrieved from: http://www.tribemix.co.uk/, 10th August 2017.

56. Paul Van Schaik, Anthony Martyr, Tim Blackman, and John Robinson. 2008. Involving persons with dementia in the evaluation of outdoor environments. CyberPsychology \& Behavior, 11 (4), pp. 415-424.

57. Joseph Volpe. 2015. The Godmother of Virtual Reality: Nonny de la Peña. Retrieved from: https:/www.engadget.com/2015/01/24/the-godmotherof-virtual-reality-nonny-de-la-pena/, 9th August 2017.

58. Jayne Wallace, John McCarthy, Peter C. Wright, and Patrick Olivier. 2013. Making design probes work. In Proceedings of the SIGCHI Conference on Human Factors in Computing Systems (CHI '13). ACM, New York, NY, USA, 3441-3450. DOI: https://doi.org/10.1145/2470654.2466473

59. Jayne Wallace, Anja Thieme, Gavin Wood, Guy Schofield, and Patrick Olivier. 2012. Enabling self, intimacy and a sense of home in dementia: an enquiry into design in a hospital setting. In Proceedings of the SIGCHI Conference on Human Factors in Computing Systems (CHI '12). ACM, New York, NY, USA, 26292638. DOI: http://dx.doi.org/10.1145/2207676.2208654

60. Jayne Wallace, Peter C. Wright, John McCarthy, David Philip Green, James Thomas, and Patrick Olivier. 2013. A design-led inquiry into personhood in dementia. In Proceedings of the SIGCHI Conference on Human Factors in Computing Systems (CHI '13). ACM, New York, NY, USA, 2617-2626. DOI: https://doi.org/10.1145/2470654.2481363

61. Jenny Waycott, Hilary Davis, Anja Thieme, Stacy Branham, John Vines, and Cosmin Munteanu. 2015. Ethical Encounters in HCI: Research in Sensitive Settings. In Proceedings of the 33rd Annual ACM Conference Extended Abstracts on Human Factors in Computing Systems (CHI EA '15). ACM, New York, NY, USA, 2369-2372. DOI: https://doi.org/10.1145/2702613.2702655

62. Patrice L. Weiss, Rachel Kizony, Uri Feintuch, and Noomi Katz. 2006. Virtual reality in neurorehabilitation. Textbook of Neural Repair and Rehabilitation, 51 (8): 182-97.

63. Yuan Ye, Mi Li, Liu Tianyi, and Shen Zhong. 2016. Storytelling in VR: light chaser's VR short film sent. In ACM SIGGRAPH 2016 VR Village (SIGGRAPH '16). ACM, New York, NY, USA. DOI: https://doi.org/10.1145/2929490.2930998 